\title{
Rituximab therapy for focal segmental glomerulosclerosis and minimal change disease in adults: a systematic review and meta-analysis
}

Panupong Hansrivijit ${ }^{*}$, Wisit Cheungpasitporn², Charat Thongprayoon ${ }^{3}$ and Nasrollah Ghahramani ${ }^{4}$

\begin{abstract}
Background: Use of rituximab (RTX) for focal segmental glomerulosclerosis (FSGS) and minimal change disease (MCD) is widely described in children. Clinical evidence in adults is limited. The objective of this study was to determine the treatment outcomes of RTX in adults with FSGS and MCD.

Methods: Ovid MEDLINE, SCOPUS, and Cochrane Database of Systematic Reviews were searched up to September 2019. Out of 699 studies, we included 16 studies describing the treatment outcomes of rituximab in adult patients with FSGS or MCD. Results were reported in remission rate and relapse rate. Serious adverse events were also reported.

Results: A total of 16 studies were included in our review and analysis. All studies were observational studies and included a total of 221 patients (23.1\% FSGS, 76.9\% MCD). Mean follow-up duration was $26.3 \pm 12.8$ months. From the analysis of five studies with FSGS patients $(n=51)$, the overall remission rate and relapse rate of RTX therapy was $53.6 \%(95 \% \mathrm{Cl}, 15.8-87.6 \%)$ and $47.3 \%(95 \% \mathrm{Cl}, 25.4-70.2 \%)$, respectively. Complete remission occurred in 42.9\%. In contrast, from the analysis of 11 studies with MCD patients $(n=170)$, the overall remission rate and relapse rate of RTX therapy was $80.3 \%(95 \% \mathrm{Cl}, 68.5-88.5 \%)$ and $35.9 \%(95 \% \mathrm{Cl}, 25.1-48.4)$, respectively. Complete remission occurred in $74.7 \%$. Subgroup analyses showed that overall remission and relapse were not different after adjusted for study year and RTX dose for both FSGS and MCD. Incidence of serious adverse events was 0.092 events/year.

Conclusions: Rituximab may be considered as an additional treatment to the standard therapy for adult patients with FSGS and MCD. Remissions and relapses are similar between FSGS and MCD. Serious adverse effects of rituximab were uncommon. We encourage further randomized controlled trials to confirm the efficacy of rituximab therapy in these patients.
\end{abstract}

Keywords: Rituximab, FSGS, Focal segmental glomerulosclerosis, MCD, Minimal change disease, Nephrotic syndrome

\footnotetext{
*Correspondence: hansrivijitp@upmc.edu

'Department of Internal Medicine, University of Pittsburgh Medical Center Pinnacle, 504 S. Front St, Suite 3C, Harrisburg, PA 17104, USA

Full list of author information is available at the end of the article
}

C C The Author(s). 2020 Open Access This article is licensed under a Creative Commons Attribution 4.0 International License, which permits use, sharing, adaptation, distribution and reproduction in any medium or format, as long as you give appropriate credit to the original author(s) and the source, provide a link to the Creative Commons licence, and indicate if changes were made. The images or other third party material in this article are included in the article's Creative Commons. licence, unless indicated otherwise in a credit line to the material. If material is not included in the article's Creative Commons licence and your intended use is not permitted by statutory regulation or exceeds the permitted use, you will need to obtain permission directly from the copyright holder. To view a copy of this licence, visit http://creativecommons.org/licenses/by/4.0/ The Creative Commons Public Domain Dedication waiver (http://creativecommons.org/publicdomain/zero/1.0/) applies to the data made available in this article, unless otherwise stated in a credit line to the data. 


\section{Background}

Minimal change disease (MCD) and focal segmental glomerulosclerosis (FSGS) are common causes of nephrotic syndrome in adults. Although MCD is more common in children, its incidence in adults is up to 15\% [1]. Similar to FSGS, adult-onset MCD may have severe clinical features and could potentially lead to end-stage kidney disease (ESKD), which is unusual for children-onset MCD [2]. Clinical presentations and steroid responsiveness of FSGS depend on the histological classification. Up to $63 \%$ of patients with primary FSGS have been reported to achieve remission after being treated with steroids [3]. The response rate of MCD to steroids was reported to be $75 \%$ [2]. However, relapses are common in both FSGS and MCD. Approximately 50\% of patients with FSGS would experience at least one relapse [4]. In adults with $\mathrm{MCD}$, relapses are frequent, occurring in $56-76 \%$ of cases [1,2].

Long term steroid therapy results in adverse clinical effects, such as dyslipidaemia, impaired fasting glucose, decreased bone mineralisation, hypertension and increased cardiovascular events. The aim of minimisation of the steroids can be achieved by adding alternative immunosuppressive agents. Several medications are considered second and third line treatment for resistant MCD or FSGS. Cyclosporine A, mycophenolate mofetil, azathioprine, tacrolimus, levamisole, cyclophosphamide and chlorambucil are most commonly used. Although, the efficacy of these medications is acceptable, their associated adverse events and toxicities would limit their use in long-term maintenance therapy.

Rituximab (RTX) is a chimeric monoclonal antibody which specifically binds to CD20-positive lymphocytes. For MCD and FSGS, the role for RTX has been well described in paediatric population. The remission rate of children with nephrotic syndromes was $44-80 \%$ in the literature [5-7]. Kronbichler et al. conducted a systematic review of RTX therapy for relapsing MCD and FSGS and found that RTX might be effective in reducing the number of relapses and sparing immunosuppressive agents [8]. In this study, treatment with RTX reduced the number of relapses per year from 1.3 to 0 relapse after therapy. Furthermore, RTX significantly reduced the severity of proteinuria and increased serum albumin level. However, remission rate was not reported in this study. Whether the efficacy of RTX remains similar in adult patients with MCD or FSGS is unknown.

To date, the remission rate of RTX therapy in adult patients with MCD or FSGS remains undetermined. Thus, we conducted a systematic review and metaanalysis to evaluate the response of RTX therapy in patients with treatment-resistant as well as treatment-naïve FSGS and MCD. We report the remission rate, and relapse rate following RTX therapy and its correlation with RTX dose.

\section{Methods \\ Information sources and search strategy}

The protocol for this systematic review and metaanalysis is under registration process with International Prospective Register of Systematic Reviews. The manuscript of this systematic review followed the Preferred Reporting Items for Systematic Reviews and MetaAnalysis (PRISMA) statement [9]. Ovid MEDLINE, SCOPUS, and the Cochrane Database were searched from the inception through September 2019. Two authors (P.H. and N.G.) performed a systematic search independently with the following search terms: "focal segmental glomerulosclerosis" OR "minimal change disease" AND "rituximab". A manual search for related additional articles through the references of the included studies was performed. Additional details regarding the search strategy utilised for each database is provided in Supplemental Document 1.

\section{Study selection}

Only articles available in English were included for further screening. Studies were included in this systematic review if they were clinical trials, or observational studies that enrolled patients age $\geq 18$ years with FSGS and MCD who were treated with rituximab therapy. Case reports and studies containing mixed paediatric and adult population without subgroup analysis were excluded. Studies containing patients with prior history of kidney transplantation were excluded. Eligible studies needed to provide the following outcomes: remissions, relapses, degree of proteinuria and serum creatinine [2]. Studies primarily reported other treatment outcomes or comprised of mixed FSGS, MCD and membranous nephropathy without subgroup analyses for FSGS or MCD alone were excluded. A complete remission was defined as proteinuria $\leq 300 \mathrm{mg} /$ day. Partial remission was defined by a decrease of the initial urinary protein loss by $50 \%$ and $\leq$ $3.5 \mathrm{~g} /$ day. Retrieved articles were independently examined for eligibility by the two authors (P.H. and N.G.). Conflicts were resolved by consensus between all authors. All references were managed through Endnote X9.3 software (Clarivate Analytics, Philadelphia, PA, USA).

\section{Data collection process}

A data collecting form was invented to gather the following data from each included study: study title, name of authors, publication year, country where the study was conducted, type of study, patients' diagnosis (FSGS or MCD or both), sample size, intervention (rituximab), total dosage of rituximab, treatment outcomes, follow- 
up duration, CD19/20 depletion rate, and serious adverse events. Risk of bias was assessed using ROBINS-I tool for non-randomized studies of interventions [10]. Quality of studies fulfilled inclusion criteria was rated as low-, moderate- or high-risk of bias.

\section{Serious adverse events}

Using U.S. Food and Drug Administration (FDA) guidelines, serious adverse events are defined as adverse events associated with treatment which lead to 1) death, 2) life threatening condition, 3) prolonged hospitalisation or 4) permanent disability or damage disrupting the quality of life [11]. In this study, the number of serious adverse event were reported.

\section{Sensitivity analysis, subgroup analysis and publication bias}

To minimise inter-study heterogeneity, sensitivity analyses and subgroup analyses were performed. Sensitivity analyses were conducted by removing one study at a time. Subgroup analyses were preformed based on RTX dosage $\left(<1500 \mathrm{mg} / \mathrm{m}^{2}\right.$ vs. $\left.\geq 1500 \mathrm{mg} / \mathrm{m}^{2}\right)$, and literature date (prior to 2015 vs. after 2015). Presence of publication bias was evaluated by Egger's regression intercept and the Funnel plot. The latter method will be used if included number of studies is greater than 10 [12].

\section{Statistical analysis}

We used the Comprehensive Meta-Analysis software version 3.3.070 (Biostat Inc., NJ, USA) to conduct the meta-analysis and SPSS version 23.0 (IBM Corp., Armonk, NY, USA) for descriptive analyses. We applied a random-effects model to pool outcomes of interest including the remission rate and relapse rate of FSGS or MCD following rituximab therapy to minimise betweenstudy variances. In addition, to compare the overall remission rate and relapse rate between FSGS and MCD patients, a subgroup analysis separating the two populations must be performed. Statistical heterogeneity of studies was assessed by the Cochran's Q test and the $\mathrm{I}^{2}$ statistic ( $\geq 75 \%$, high heterogeneity; $51-75 \%$, moderate heterogeneity; $26-50 \%$, low heterogeneity; $\leq 25 \%$, insignificant heterogeneity) [13]. The correlations between variants were analysed by Pearson's correlation. Continuous data obtained from descriptive analysis were presented in mean \pm standard deviation (SD) or median \pm interquartile range (IQR), depending on data distribution. $P$-value less than 0.05 is considered statistically significant.

\section{Results}

\section{Study characteristics}

A total of 699 potential eligible articles were identified from our literature search. The flowchart of systematic literature review is illustrated in Fig. 1. A total of 16 studies were included in our systematic review and a total of 14 studies were included in our meta-analyses. All included studies were observational studies. Twelve of 16 were in prospective and four of them were in retrospective design. The studies included a total of 221 patients. Fifty-one patients (23.1\%) had FSGS as their primary disease while 170 patients (76.9\%) had MCD. The study characteristics are demonstrated in Table 1. Most patients (94.3\%) were diagnosed with steroid resistant, frequent relapsing, or steroid dependent disease. Only two studies $(n=14)$ reported results relating to treatment naive patients. All patients were treated with rituximab with a total median dose of $1500 \mathrm{mg} / \mathrm{m}^{2}$ (range 375-3375 mg). However, the protocol for rituximab therapy varies from study to study. B-cell depletion rate, defined by depletion of CD19 and CD20-positive cells, was $100 \%$ in all reported patients.

\section{Remissions and relapse of FSGS}

We excluded Ruggenenti et al. [22] from meta-analysis of overall remission as this study included patients who were already in remission. Likewise, Sugiura et al. [16] was excluded as they included mixed population of patients in remission and those who were not. A total of 51 patients from five studies were identified. By using random-effects model of meta-analysis, we found that the overall remission of FSGS following RTX therapy was $53.6 \%$ (95\% CI, $15.8-87.6 \%$; $\mathrm{I}^{2}=74.4 \%$; Fig. 2a). Complete remission was $42.9 \%$ (95\% CI, 10.8-82.3\%; $\left.\mathrm{I}^{2}=72.2 \%\right)$ and partial remission was $10.7 \%(95 \% \mathrm{CI}$, 7.0-59.2\%; $\mathrm{I}^{2}=59.3 \%$ ). Mean follow-up duration among FSGS patients was $18.7 \pm 9.0$ months. The relapse rate of FSGS in patients who were treated with rituximab was 47.3\% (95\% CI, 25.4-70.2\%; $\mathrm{I}^{2}=35.4 \%$; Fig. 2b). These results remained statistically significant on sensitivity analyses.

In addition, we performed a subgroup analysis of FSGS remission and relapse based on study year (prior to 2015 versus 2015 and after) and RTX dosing. We defined low-dose RTX as $<1500 \mathrm{mg} / \mathrm{m}^{2}$, and high-dose RTX as $\geq 1500 \mathrm{mg} / \mathrm{m}^{2}$ of total RTX received. There was no significant difference in remission or relapse after adjusted for RTX dosing and study year. Table 2 demonstrates subgroup analyses of FSGS patients treated with RTX therapy.

\section{Remissions and relapse of MCD}

Eleven studies of MCD patients $(n=170)$ remained in the analysis after exclusion of studies containing FSGS patients. The overall remission rate was $80.3 \%$ after RTX therapy (95\% CI, 68.5-88.5\%; $\mathrm{I}^{2}=46.4 \%$ ). This is illustrated in Fig. 2c. We found that the complete remission rate in MCD patients was $74.7 \%$ (95\% CI, 62.5-84.0\%; 


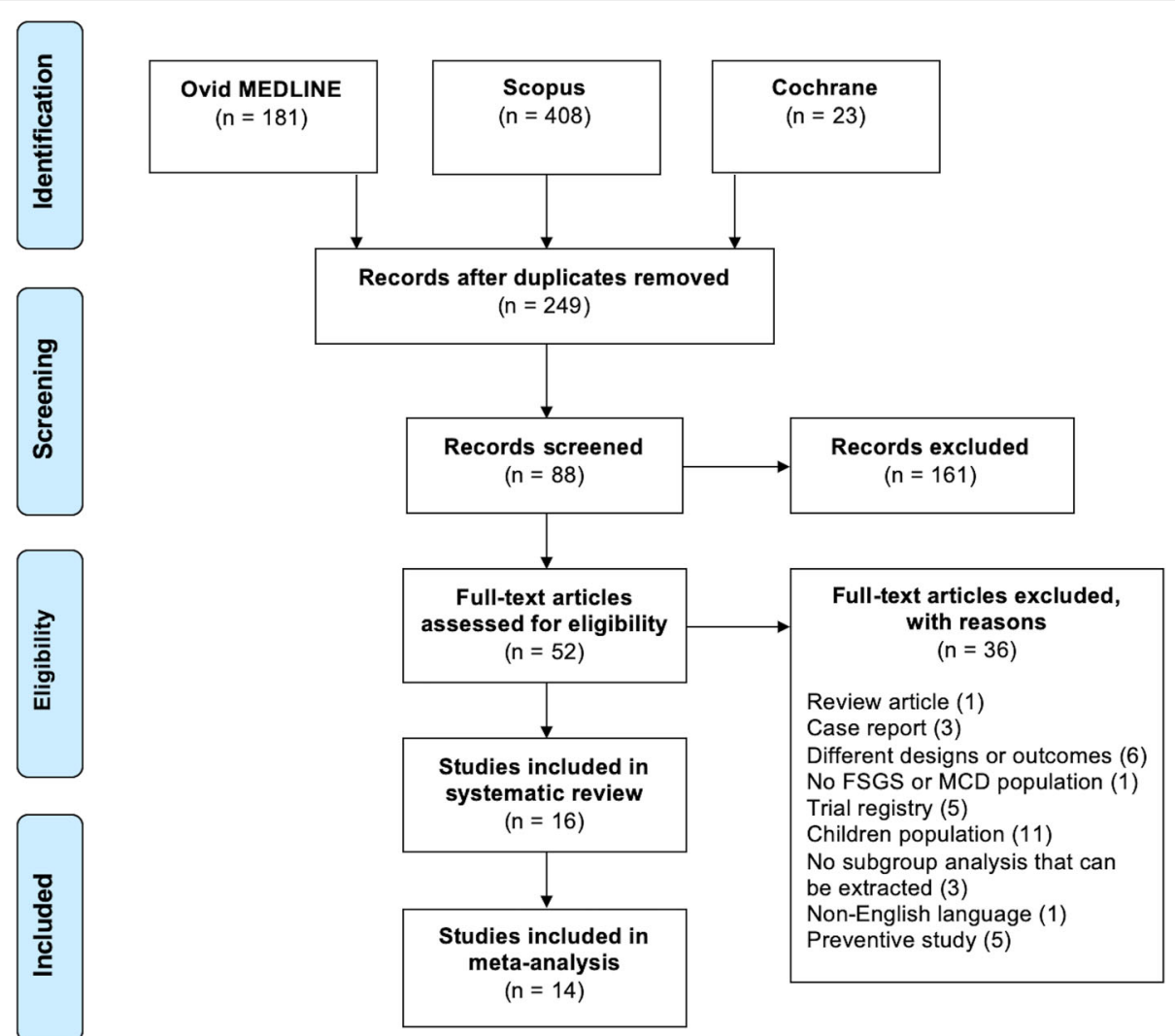

Fig. 1 Algorithm illustrating the literature search protocol. Search criteria applied to observational study, clinical trial, systematic review, metaanalysis, clinical study, comparative study, controlled clinical trial, randomized controlled trial, clinical conference, human subjects, multi-center study, article, conference paper, editorial. Only studies included patients age more than 18 years are included

$\left.\mathrm{I}^{2}=15.5 \%\right)$ while partial remission was $5.6 \%(95 \% \mathrm{CI}$, 9.9-24.8\%; $\left.\mathrm{I}^{2}=0 \%\right)$. With a mean follow-up duration of $27.6 \pm 13.5$ months, relapse occurred in $35.9 \%$ (95\% CI, 25.1-48.4\%; $\mathrm{I}^{2}=46.8 \%$; Fig. 2d) of MCD patients who achieved remission following RTX therapy. The results remained significant on sensitivity analyses.

For subgroup analysis, we found no significant difference in remission or relapse after adjusted for study year (prior to 2015 versus 2015 and after) and RTX dosing $\left(<1500 \mathrm{mg} / \mathrm{m}^{2}\right.$ versus $\left.\geq 1500 \mathrm{mg} / \mathrm{m}^{2}\right)$ (Table 2).

\section{Subgroup analysis of remission and relapse between FSGS and MCD}

We performed a subgroup analysis comparing the overall remission and relapse between patients with FSGS and patients with MCD. The mean follow-up duration was $26.3 \pm 12.8$ months. Although the overall remission rate of MCD patients was higher than those with FSGS, the difference did not reach statistical significance (80.3\% for MCD and 53.6\% for FSGS; Q-value =1.661; $p=0.678$ ). Likewise, a subgroup analysis on the relapse rate between FSGS and MCD patients showed no statistical significance $(47.3 \%$ for FSGS and $35.9 \%$ for MCD; Q-value $=0.705 ; p=0.401)$.

\section{Reported adverse events}

From all 16 studies, rituximab is well tolerated. Serious adverse events were reported in only six studies. Serious side effects include cutaneous eruption/type 1 hypersensitivity/fixed drug eruption, infusion reaction, leukopaenia, and pneumonia. By analysing all 16 studies, using random-effects model, the incidence of serious adverse events was 0.092 events per year (95\% CI, 0.056-0.148; $\left.\mathrm{I}^{2}=0 \%\right)$. There was a positive correlation between RTX dose and severe adverse events rate $\left(r^{2}=0.187 ; p=0.03\right)$.

\section{Evaluation for publication Bias}

Publication bias was evaluated by the Funnel plot of standard error as well as Egger's regression intercept. Here, we reported the Funnel plot and Egger's test on both overall remission and relapse. The Funnel plots for publications reporting remission and relapse of pooled FSGS and MCD were illustrated in Fig. 3. Egger's regression intercept for overall remission and for disease relapse did not suggest possibility of publication bias $(p=$ 


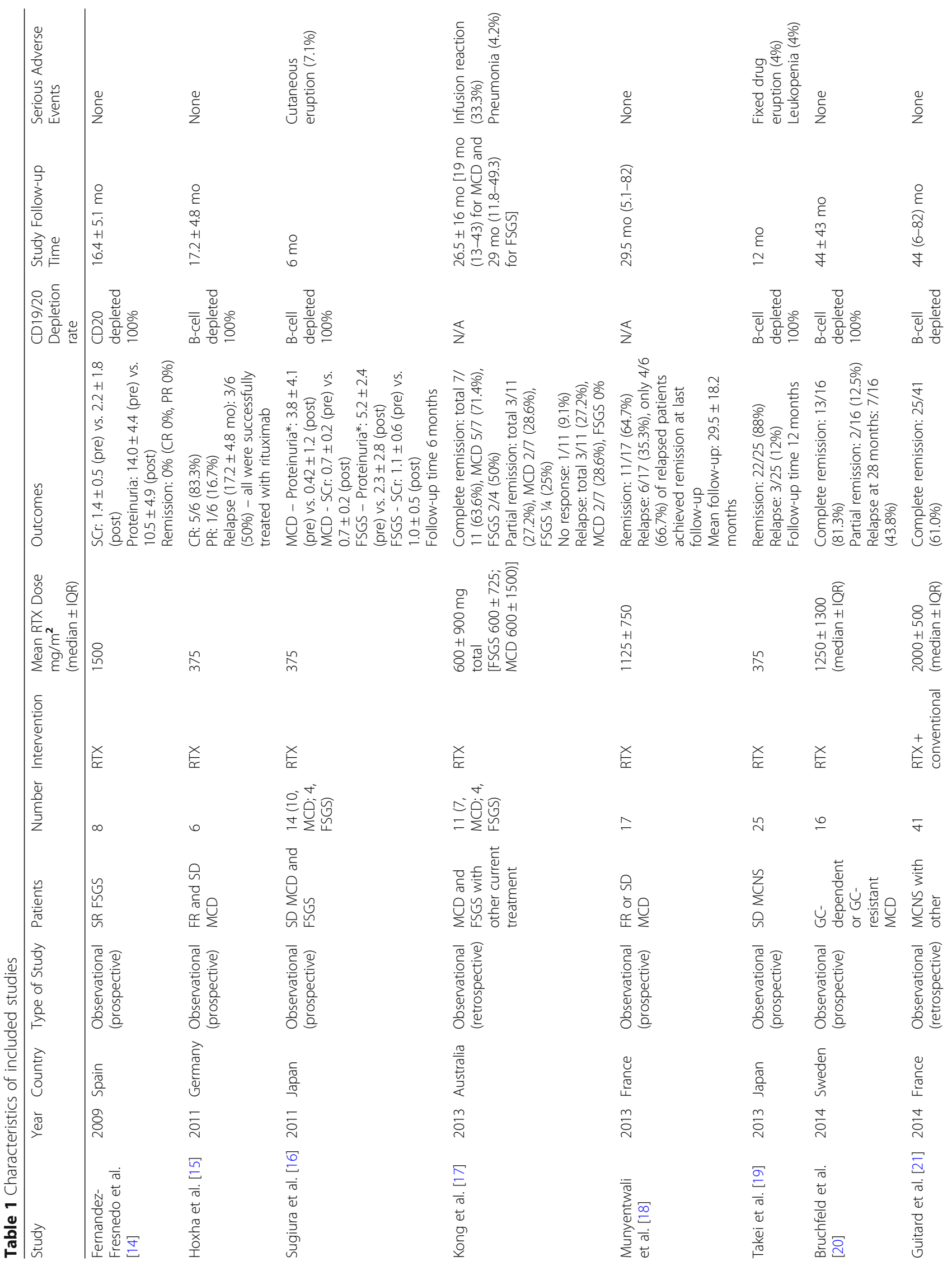




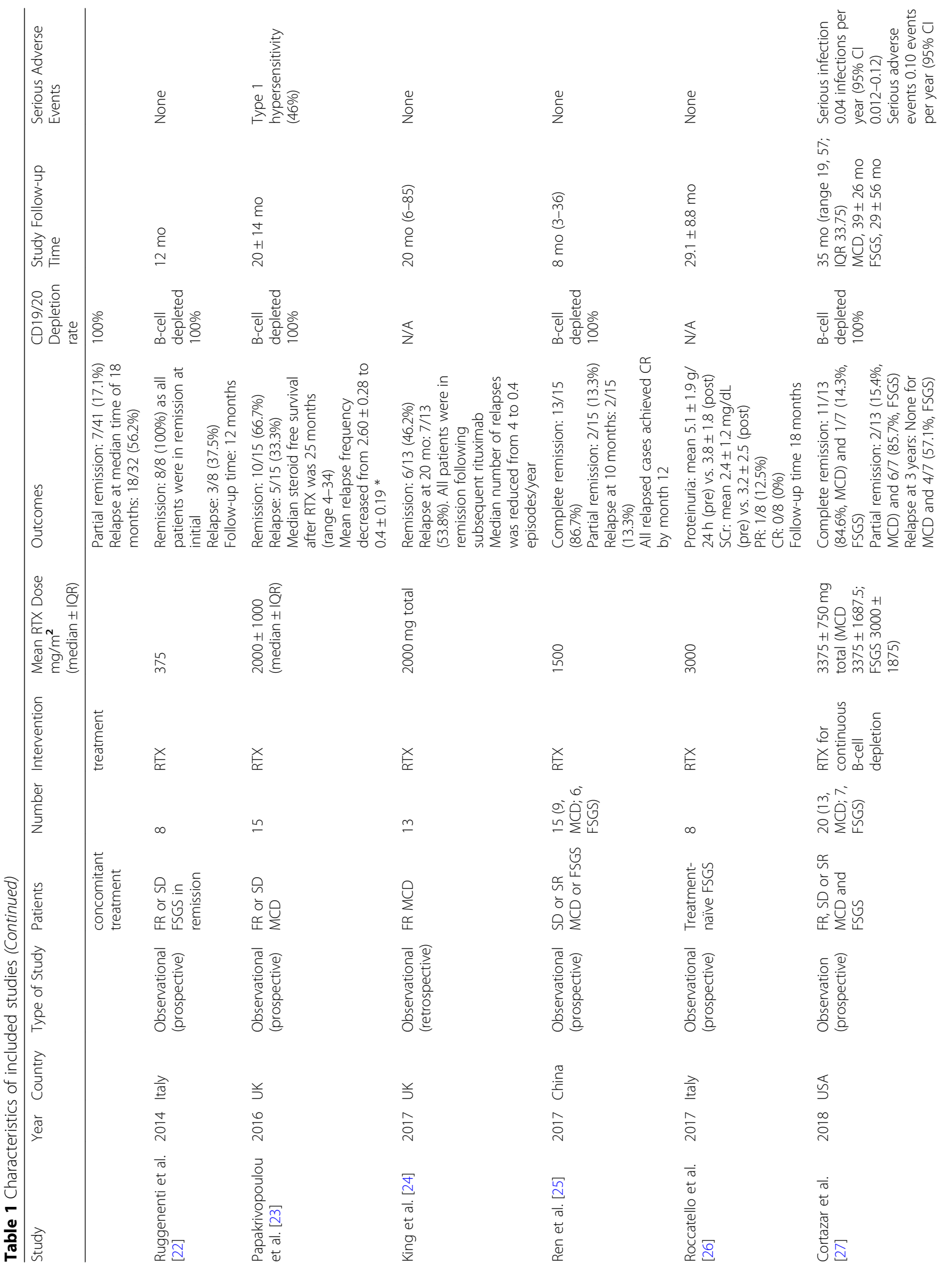




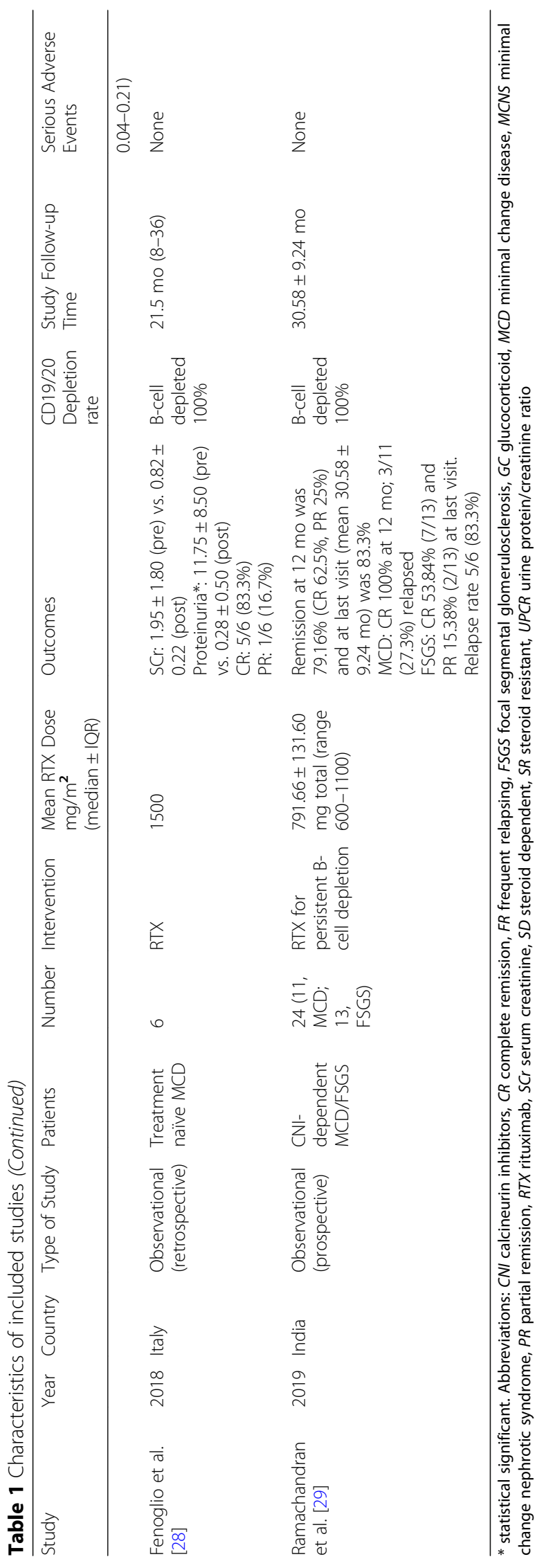




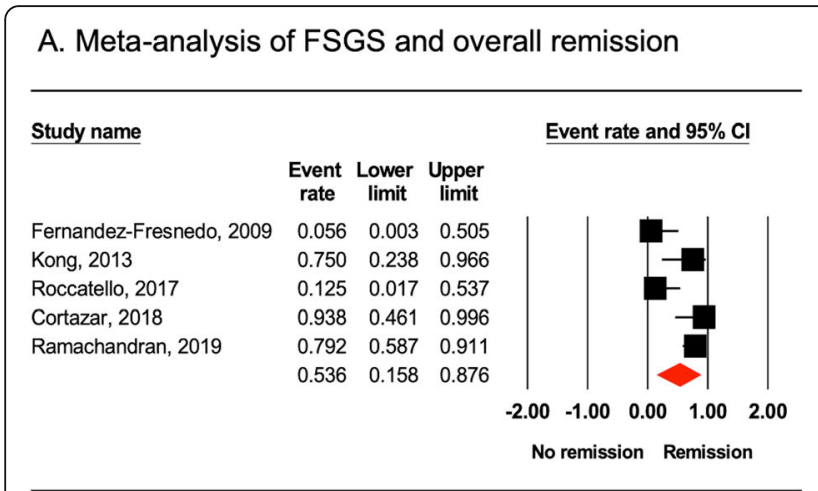

\section{Meta-analysis of MCD and overall remission}

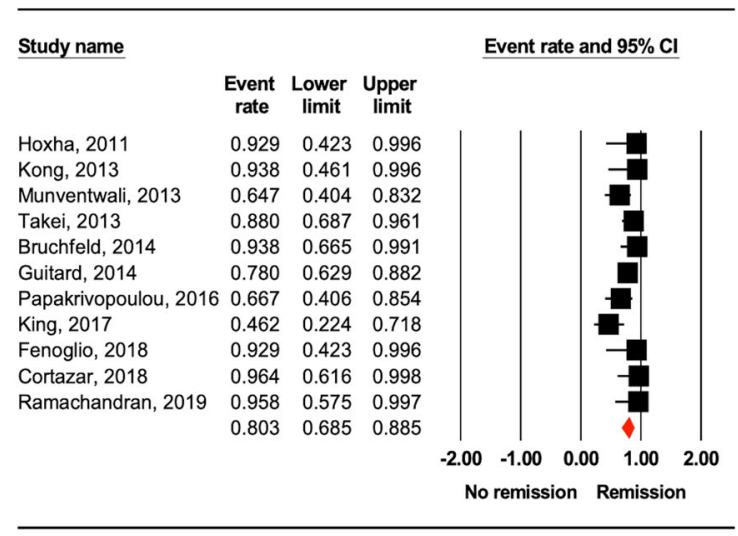

\section{B. Meta-analysis of FSGS and relapse}

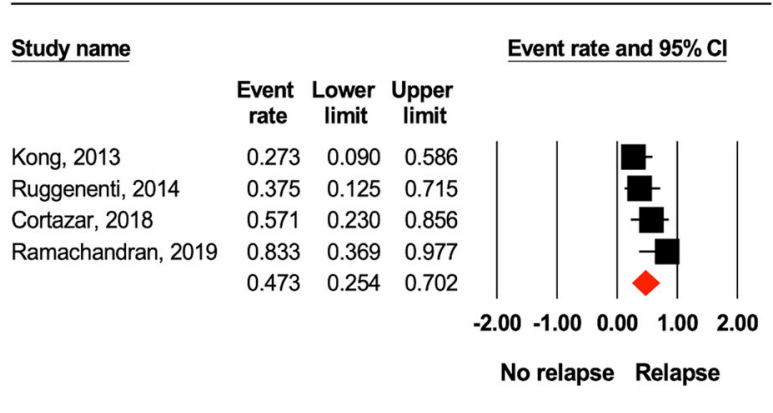

D. Meta-analysis of MCD and relapse

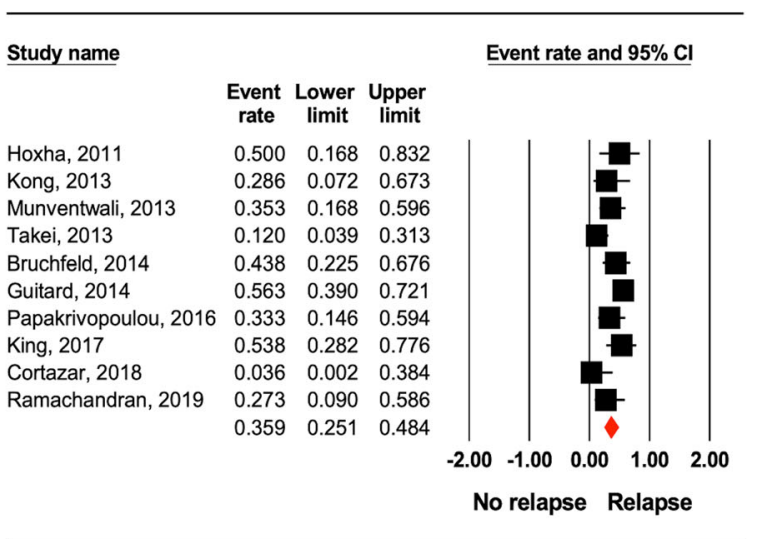

Fig. 2 Forest plots obtained from meta-analyses. a Overall remission in FSGS patients treated with rituximab. b Relapse in FSGS patients treated with rituximab. c Overall remission in MCD patients treated with rituximab. d Relapses in MCD patients treated with rituximab

0.575 and $p=0.511$ for overall remission and relapse, respectively).

\section{Discussion}

Our results suggest that rituximab may be considered as an additional treatment for FSGS and preferably MCD in adults. In this study, we reported that $53.6 \%$ of FSGS patients achieved remission as compared to $80.3 \%$ in MCD patients. With a mean follow-up of at least two years, up to $47.3 \%$ of FSGS patients and $35.9 \%$ of MCD patients relapsed. However, although FSGS patients had lower overall remission rate with slightly higher relapses in comparison to MCD patients, these differences were not statistically significant because there was significant variance within each group. Audience should be cautious when interpret this finding as there was no direct comparison to the standard treatment or concomitant therapy. Furthermore, the results maybe underpowered given smaller sample size in FSGS group. In addition, the burden of nephrotic syndrome at the time of treatment with rituximab was not universal across studies. It is possible that patients with mild disease would respond better to rituximab therapy. Randomized controlled studies are required to increase the power of the analysis and to distinguish the efficacy of rituximab therapy in FSGS and MCD patients in comparison with the standard treatment.

As a reference, the response of treatment-naïve FSGS and MCD to steroids was reported to be 63 and $75 \%$ in the literature, respectively $[2,3]$. At least $50 \%$ of patients with FSGS or MCD would experience relapses through the course of standard treatment $[1,2,4]$. In this study, we also found that the remission rate and relapse rate remained constant over time. However, it is also worth noting that our reported relapse rate might be underreported as relapses can increase if patients are followed for a longer period of time. One single-centre prospective study has demonstrated that among patients diagnosed with frequently relapsing or treatment-resistant MCD and FSGS, younger age at diagnosis was significantly associated with increased incidence of disease relapse after rituximab therapy [22].

It remains unclear how rituximab leads to remission in patients with FSGS and MCD. Rituximab is a monoclonal antibody directed against CD20-positive lymphocytes. The use of rituximab has been approved by the 
Table 2 Subgroup analyses of included studies

\begin{tabular}{lllll}
\hline & $N$ & Event, $\%$ & $95 \% \mathrm{Cl}$ & \\
\hline FSGS & & & & \\
Remission & & & & \\
RTX $<1500 \mathrm{mg} / \mathrm{m}^{2}$ & 2 & 78.5 & $59.7-90.0$ & \\
RTX $\geq 1500 \mathrm{mg} / \mathrm{m}^{2}$ & 3 & 48.4 & $4.0-99.5$ & $\mathrm{Q}=0.235, p=0.628$ \\
$\quad$ Prior to 2015 & 2 & 31.7 & $1.0-95.6$ & \\
2015 and later & 3 & 65.3 & $14.7-95.4$ & $\mathrm{Q}=0.367, p=0.545$ \\
Relapse & & & & \\
RTX $<1500 \mathrm{mg} / \mathrm{m}^{2}$ & 3 & 45.3 & $18.1-75.6$ & \\
RTX $\geq 1500 \mathrm{mg} / \mathrm{m}^{2}$ & 1 & 57.1 & $23.0-85.6$ & $\mathrm{Q}=0.220, p=0.639$ \\
Prior to 2015 & 2 & 31.8 & $15.0-55.2$ & \\
2015 and later & 2 & 67.3 & $37.6-87.5$ & $\mathrm{Q}=3.445, p=0.063$ \\
MCD & & & & \\
Remission & & & & \\
RTX $<1500 \mathrm{mg} / \mathrm{m}^{2}$ & 6 & 86.5 & $72.0-94.1$ & \\
RTX $\geq 1500 \mathrm{mg} / \mathrm{m}^{2}$ & 5 & 73.4 & $53.2-87.1$ & $\mathrm{Q}=1.669 ; p=0.196$ \\
Prior to 2015 & 6 & 81.6 & $70.2-89.3$ & \\
2015 and later & 5 & 79.7 & $51.8-93.5$ & $\mathrm{Q}=0.027, p=0.871$ \\
Relapse & & & &
\end{tabular}

U.S. FDA for B-cell-mediated malignancies and connective tissue diseases. Infiltration of lymphocytes has been described in transplanted kidneys affected by FSGS recurrence [30] which suggested that FSGS is an antibodymediated disease. However, the actual pathogenesis of
FSGS remains undiscovered. Rituximab was shown to play roles in B-cell-independent mechanisms as well. For instance, rituximab was demonstrated to regulate the activity of acid-sphyngomyelinase (ASMase), which are essential for signalling molecules on the pododcytes [31, 32]. Perosa et al. reported that rituximab might cross react with sphingomyelin-phosphodiesterase-acid-like-3b (SMPDL-3b) [33]. Reduction in SMPDL-3b-positive podocytes was observed in biopsies showing FSGS [34]. Rather than acting on antibody production directly, rituximab might prevent actin cytoskeleton remodelling in the podocytes by preserving sphingolipid-related enzymes and SMPDL-3b and ASMase activity. Further basic science researches are needed to determine the role of rituximab in the glomerular level.

We have also shown that rituximab was well tolerated in all studies with the incidence of serious adverse events of 0.092 events per year. Administering higher dose of rituximab was associated with higher adverse events. This finding is similar to what previously described in chronic lymphocytic leukaemia (CLL). Patients with CLL are usually treated with high dose rituximab, thus, the incidence of adverse events is higher [35]. Although there are literatures suggesting that relapse usually occurred in the setting of B-cell recovery $[18,23]$, the role of B-cell depletion-targeted RTX therapy to prevent relapse, however, requires further investigations using randomized controlled trials.

To the best of our knowledge, this is the first metaanalysis describing the treatment outcomes of rituximab therapy for FSGS and MCD in adults. However, our study has some limitations. First, all included studies were observational studies making it is difficult to conclude if rituximab is more effective than the standard

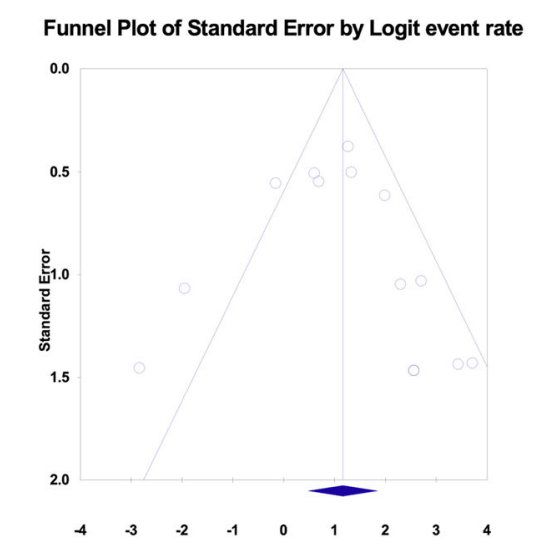

A

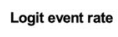

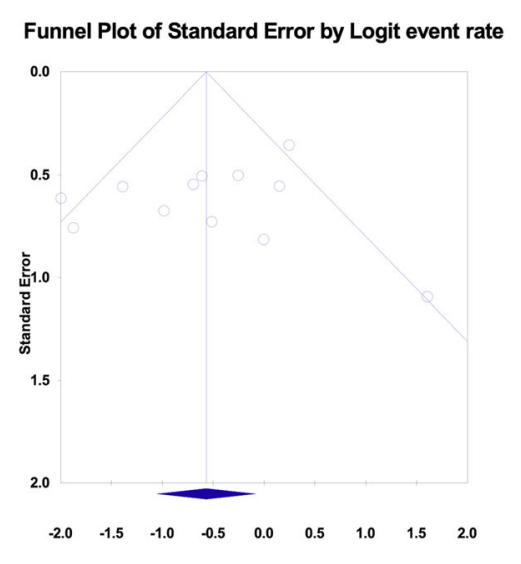

B

Fig. 3 Funnel plots evaluating publication bias. a Funnel plot for publications reported the overall remission in patients with pooled FSGS and MCD. b Funnel plot for publications reported the relapses in patients with pooled FSGS and MCD 
treatments due to lack of comparisons and concomitant therapy. Second, most MCD patients included in our analyses were diagnosed based upon the initial biopsy. Whether these patients potentially progressed to FSGS on subsequent biopsies remains unknown. Third, the histological subtype of FSGS was not identified as this would impact the response to treatment as well. Fourth, only five studies were available for analysis of FSGS. More studies on adult patients with FSGS are needed. Finally, our study demonstrated moderate degree of heterogeneity with most $\mathrm{I}^{2}$ ranging from 51 to $75 \%$. However, we utilised random-effects and mixed-effects model along with sensitivity analyses to minimise the contamination from heterogeneity. Several clinical trials proving the efficacy of rituximab in treatment of FSGS and MCD are currently being undertaken including RIFIREINS and TURING study (NCT03970577, ISRCTN16948923, JPRN-UMIN000005231, JPRNUMIN000019844, CTRI/2018/01/011316, EUCTR2017003366-27-NL).

\section{Conclusions}

Rituximab may be considered as an additional treatment to the standard therapy for FSGS and MCD in adult patients. Remissions and relapses are similar between FSGS and MCD group. Serious adverse effects of rituximab were uncommon. We encourage further randomized controlled trials to confirm the efficacy of rituximab therapy in these patients.

\section{Supplementary information}

Supplementary information accompanies this paper at https://doi.org/10. 1186/s12882-020-01797-7.

\section{Additional file 1.}

\section{Abbreviations}

RTX: Rituximab; FSGS: Focal segmental glomerulosclerosis; MCD: Minimal change disease; ESKD: End-stage kidney disease; PRISMA: Preferred Reporting Items for Systematic Reviews and Meta-analysis; FDA: Food and Drug Administration

\section{Acknowledgements}

We would like to thank our Meta-analysis Statistician Team for consultation and advice. An abstract of this research was presented at the National Kidney Foundation Spring Clinical Meeting 2020

\section{Authors' contributions}

P.H. and N.G. created the protocol for this study. P.H. and W.C. searched for eligible literatures. P.H. and C.T. extracted the data. P.H. analysed the data and drafted the manuscript. P.H., W.C., C.T., and N.G. revised the manuscript for submission. The authors read and approved the final manuscript.

\section{Funding}

No funding reported for this study.

\section{Availability of data and materials}

The datasets generated and/or analysed during the current study are available in Table 1, Figs. 1, 2 and Supplemental Document 1.
Ethics approval and consent to participate

Not applicable.

\section{Consent for publication}

Not applicable.

\section{Competing interests}

Charat Thongprayoon, MD is a member of the editorial board for BMC Nephrology journal. Other authors declared no conflict of interest.

\section{Author details}

${ }^{1}$ Department of Internal Medicine, University of Pittsburgh Medical Center Pinnacle, 504 S. Front St, Suite 3C, Harrisburg, PA 17104, USA. Division of Nephrology, University of Mississippi Medical Center, Jackson, MS 39216 , USA. ${ }^{3}$ Division of Nephrology and Hypertension, Mayo Clinic, Rochester, MN 55905, USA. ${ }^{4}$ Division of Nephrology, Department of Medicine, Penn State University College of Medicine, Hershey, PA 17033, USA.

Received: 5 December 2019 Accepted: 6 April 2020

Published online: 15 April 2020

\section{References}

1. Nolasco F, Cameron JS, Heywood EF, Hicks J, Ogg C, Williams DG. Adultonset minimal change nephrotic syndrome: a long-term follow-up. Kidney Int. 1986:29(6):1215-23.

2. Waldman M, Crew RJ, Valeri A, Busch J, Stokes B, Markowitz G, D'Agati V, Appel G. Adult minimal-change disease: clinical characteristics, treatment, and outcomes. Clin J Am Soc Nephrol. 2007;2(3):445-53.

3. Chun MJ, Korbet SM, Schwartz MM, Lewis EJ. Focal segmental glomerulosclerosis in nephrotic adults: presentation, prognosis, and response to therapy of the histologic variants. J Am Soc Nephrol. 2004;15(8): 2169-77.

4. Troyanov S, Wall CA, Miller JA, Scholey JW, Cattran DC. Focal and segmental glomerulosclerosis: definition and relevance of a partial remission. J Am Soc Nephrol. 2005;16(4):1061-8

5. Ito S, Kamei K, Ogura M, Udagawa T, Fujinaga S, Saito M, Sako M, lijima K. Survey of rituximab treatment for childhood-onset refractory nephrotic syndrome. Pediatr Nephrol (Berlin, Germany). 2013;28(2):257-64.

6. Kemper MJ, Gellermann J, Habbig S, Krmar RT, Dittrich K, Jungraithmayr T, Pape L, Patzer L, Billing $H$, Weber $L$, et al. Long-term follow-up after rituximab for steroid-dependent idiopathic nephrotic syndrome. Nephrol Dial Transplant. 2012;27(5):1910-5.

7. Prytula A, lijima K, Kamei K, Geary D, Gottlich E, Majeed A, Taylor M, Marks SD, Tuchman S, Camilla R, et al. Rituximab in refractory nephrotic syndrome. Pediatr Nephrol (Berlin, Germany). 2010;25(3):461-8.

8. Kronbichler A, Kerschbaum J, Fernandez-Fresnedo G, Hoxha E, Kurschat CE, Busch M, Bruchfeld A, Mayer G, Rudnicki M. Rituximab treatment for relapsing minimal change disease and focal segmental glomerulosclerosis: a systematic review. Am J Nephrol. 2014;39(4):322-30.

9. Moher D, Liberati A, Tetzlaff J, Altman DG. Preferred reporting items for systematic reviews and meta-analyses: the PRISMA statement. PLoS Med. 2009;6(7):e1000097.

10. Sterne JA, Hernan MA, Reeves BC, Savovic J, Berkman ND, Viswanathan M, Henry D, Altman DG, Ansari MT, Boutron I et al: ROBINS-l: a tool for assessing risk of bias in non-randomised studies of interventions. (17561833 (Electronic))

11. U.S. Food and Drug Administration. WHat is a Serious Adverse Event? https://www.fda.gov/safety/reporting-serious-problems-fda/what-seriousadverse-event. Accessed on 29 Feb 2020.

12. Easterbrook PJ, Berlin JA, Gopalan R, Matthews DR. Publication bias in clinical research. Lancet. 1991;337(8746):867-72.

13. Higgins JP, Thompson SG, Deeks JJ, Altman DG. Measuring inconsistency in meta-analyses. BMJ. 2003:327(7414):557-60.

14. Fernandez-Fresnedo G, Segarra A, González E, Alexandru S, Delgado R, Ramos N, Egido JS, Praga M. Rituximab treatment of adult patients with steroid-resistant focal segmental glomerulosclerosis. Clin J Am Soc Nephrol. 2009:4(8):1317-23.

15. Hoxha E, Stahl RAK, Harendza S. Rituximab in adult patients with immunosuppressive-dependent minimal change disease. Clin Nephrol. $2011 ; 76(2): 151-8$. 
16. Sugiura H, Takei T, Itabashi M, Tsukada M, Moriyama T, Kojima C, Shiohira T, Shimizu A, Tsuruta Y, Amemiya N, et al. Effect of single-dose rituximab on primary glomerular diseases. Nephron Clin Pract. 2011;117(2):c98-c105.

17. Kong WY, Swaminathan R, Irish A. Our experience with rituximab therapy for adult-onset primary glomerulonephritis and review of literature. Int Urol Nephrol. 2013:45(3):795-802.

18. Munyentwali H, Bouachi $K$, Audard V, Remy P, Lang P, Mojaat R, Deschênes G, Ronco PM, Plaisier EM, Dahan KY. Rituximab is an efficient and safe treatment in adults with steroid-dependent minimal change disease. Kidney Int. 2013:83(3):511-6.

19. Takei T, Itabashi M, Moriyama T, Kojima C, Shiohira S, Shimizu A, Tsuruta Y, Ochi A, Amemiya N, Mochizuki T, et al. Effect of single-dose rituximab on steroid-dependent minimal-change nephrotic syndrome in adults. Nephrol Dial Transplant. 2013;28(5):1225-32.

20. Bruchfeld A, Benedek S, Hilderman M, Medin C, Snaedal-Jonsdottir S, Korkeila M. Rituximab for minimal change disease in adults: long-term follow-up. Nephrol Dial Transplant. 2014:29(4):851-6.

21. Guitard J, Hebral AL, Fakhouri F, Joly D, Daugas E, Rivalan J, Guigonis V, Ducret F, Presne C, Pirson Y, et al. Rituximab for minimal-change nephrotic syndrome in adulthood: predictive factors for response, long-term outcomes and tolerance. Nephrol Dial Transplant. 2014:29(11):2084-91.

22. Ruggenenti $P$, Ruggiero $B$, Cravedi $P$, Vivarelli $M$, Massella L, Marasà $M$, Chianca A, Rubis N, Ene-lordache B, Rudnicki M, et al. Rituximab in steroiddependent or frequently relapsing idiopathic nephrotic syndrome. J Am Soc Nephrol. 2014;25(4):850-63.

23. Papakrivopoulou E, Shendi AM, Salama AD, Khosravi M, Connolly JO, Trompeter R. Effective treatment with rituximab for the maintenance of remission in frequently relapsing minimal change disease. Nephrology. 2016;21 (10):893-900.

24. King C, Logan S, Smith SW, Hewins P. The efficacy of rituximab in adult frequently relapsing minimal change disease. Clin Kidney J. 2017;10(1):16-9.

25. Ren $H$, Lin L, Shen P, Li X, Xie J, Pan X, Zhang W, Chen N. Rituximab treatment in adults with refractory minimal change disease or focal segmental glomerulosclerosis. Oncotarget. 2017;8(55):93438-43.

26. Roccatello D, Sciascia S, Rossi D, Alpa M, Naretto C, Radin M, Barreca A, Fenoglio R, Baldovino S, Menegatti E. High-dose rituximab ineffective for focal segmental Glomerulosclerosis: a long-term observation study. Am J Nephrol. 2017;46(2):108-13

27. Cortazar FB, Rosenthal J, Laliberte K, Niles JL. Continuous B-cell depletion in frequently relapsing, steroid-dependent and steroid-resistant nephrotic syndrome. Clin Kidney J. 2018;12(2):224-31.

28. Fenoglio R, Sciascia S, Beltrame G, Mesiano P, Ferro M, Quattrocchio G, Menegatti E, Roccatello D. Rituximab as a front-line therapy for adult-onset minimal change disease with nephrotic syndrome. Oncotarget. 2018;9(48):28799-804.

29. Ramachandran R, Bharati J, Rao I, Kashif AW, Nada R, Minz R, Gupta KL, Kohli HS. Persistent CD-19 depletion by rituximab is cost-effective in maintaining remission in calcineurin-inhibitor dependent podocytopathy. Nephrology. 2019;24(12):1241-47.

30. de Oliveira JG, Xavier P, Carvalho E, Ramos JP, Magalhaes MC, Mendes AA, Faria V, Guerra LE. T lymphocyte subsets and cytokine production by graftinfiltrating cells in FSGS recurrence post-transplantation. Nephrol Dial Transplant. 1999;14(3):713-6.

31. Bezombes C, Grazide S, Garret C, Fabre C, Quillet-Mary A, Muller S, Jaffrezou $J P$, Laurent G. Rituximab antiproliferative effect in B-lymphoma cells is associated with acid-sphingomyelinase activation in raft microdomains. Blood. 2004;104(4):1166-73.

32. Bollinger $C R$, Teichgraber $V$, Gulbins E. Ceramide-enriched membrane domains. Biochim Biophys Acta. 2005;1746(3):284-94

33. Perosa F, Favoino E, Caragnano MA, Dammacco F. Generation of biologically active linear and cyclic peptides has revealed a unique fine specificity of rituximab and its possible cross-reactivity with acid sphingomyelinase-like phosphodiesterase 3b precursor. Blood. 2006;107(3):1070-7.

34. Fornoni A, Sageshima J, Wei C, Merscher-Gomez S, Aguillon-Prada R, Jauregui AN, Li J, Mattiazzi A, Ciancio G, Chen L, et al. Rituximab targets podocytes in recurrent focal segmental glomerulosclerosis. Sci Transl Med. 2011;3(85):85ra46.

35. Simkovic M, Vodarek P, Motyckova M, Zak P, Smolej L. Rituximab infusionrelated toxicity in patients with chronic lymphocytic leukemia. Vnitr Lek. 2015;61(7-8):626-32.

\section{Publisher's Note}

Springer Nature remains neutral with regard to jurisdictional claims in published maps and institutional affiliations.
Ready to submit your research? Choose BMC and benefit from:

- fast, convenient online submission

- thorough peer review by experienced researchers in your field

- rapid publication on acceptance

- support for research data, including large and complex data types

- gold Open Access which fosters wider collaboration and increased citations

- maximum visibility for your research: over $100 \mathrm{M}$ website views per year

At BMC, research is always in progress.

Learn more biomedcentral.com/submissions 